Europe's Journal of Psychology, 6(3), pp. 46-70

www.ejop.org

\title{
Is It You or Is It Me? Contrasting Effects of Ridicule Targeting Other People Versus the Self
}

Leslie M. Janes

Brescia Univ ersity College

James M. Olson

University of Western Ontario

\begin{abstract}
In this paper, we describe a program of research on the topic of ridicule, which explored the differing effects of observing either ridicule directed at other people or selfdisparaging ridicule. In three studies, participants listened to humor that either ridiculed another person, ridiculed the self (the person expressing the humor), or involved no ridicule. Results in two studies showed that observing ridicule that targeted another person led participants to conform more to the alleged attitudes of others and to behave in ways suggesting a heightened fear of failure, compared to self-ridicule or no ridicule. In contrast, results in a third study showed that observing self-disparaging ridicule led participants to generate more creative ideas, compared to other-ridicule or no ridicule. The implications of these "inhibiting" effects of other-ridicule and "disinhibiting" effects of self-ridicule are discussed.
\end{abstract}

Keywords: ridicule, disparagement humor, self-ridicule, conformity, creativity

Ridicule is defined as "the act of making someone the object of scornful laughter" (Webster's New World Dictionary, 2002). This type of humor is common in modernday society. It is a staple in late-night comedy shows, political campaigns, advertising, and even prime time television. Stocking, Sopolsky, and Zillmann (1977) did a content analysis of humor in prime time television for one week. An incident of humor was recorded as "hostile" if a person or thing was disparaged. They found that $69 \%$ of all humorous incidents in prime time were hostile. 
Of course, ridicule is not a modern phenomenon-indeed, it has been around for millennia. In an examination of the humor in the Old Testament, Koestler (1964) found that most of the references to humor or laughter were linked with scorn, derision, mockery, or contempt. Only 2 of the 29 humor references in the Old Testament were categorized as "good-natured." More recently, Gruner (1978) has argued that "ridicule is the basic component of all humorous material" (p. 14).

Ridicule is one form of disparagement humor, a broader category that has been defined as humorous material in which one party is victimized, belittled, humiliated, or suffers some misfortune or act of aggression (Zillmann, 1983). Most disparagement humor targets groups or members of groups (e.g., women, ethnic groups, lawyers) rather than individuals. Ridicule can be distinguished from disparagement humor in that it tends to be more personal in nature and is typically directed at an individual rather than a group (Wilson, 1979).

In this paper, we describe a program of research we have conducted on the topic of ridicule, exploring the differing effects of ridicule directed at other people versus the self. We begin by reviewing some past theories and empirical studies by other researchers on disparagement humor, which have identified important consequences of such humor on listeners' attitudes and stereotypes. We then turn to our own research.

\section{Theories of Disparagement Humor}

Several theoretical models have been proposed to explain the prevalence and consequences of disparagement humor (and, by implication, ridicule). We briefly review four of these models in the following sections (for more detailed reviews, see Ferguson \& Ford, 2008; Martin, 2007).

Psychoanalytic Theory

Freud (1905/1960) theorized that we enjoy disparagement humor because the comedic façade disguises the hostility of the content. Thus, we can vent our aggressive feelings in a socially acceptable manner. From this perspective, disparagement humor "provides the humorist with a relatively benign means of expressing and satisfying unconscious, socially unacceptable impulses" (Ferguson \& Ford, 2008, p. 285). Furthermore, according to Freud, expressing these aggressive impulses through humor has a cathartic effect-a reduction of hostile psychic energy. 
In empirical tests, however, the catharsis hypothesis has received little support. In fact, researchers have typically found that exposure to hostile humor actually increases expressions of aggression (e.g., Baron, 1978; Ryan \& Kanjorski, 1998). In Baron's study, for example, male college students were exposed to non-humorous materials, hostile humor, or non-hostile humor. The students were then given an opportunity to aggress against a male confederate. Results of the study indicated that students in the hostile humor condition aggressed more than did those in the non-humor condition, whereas those students in the non-hostile humor condition aggressed less than those in the non-humor condition (Baron, 1978). It is true that people sometimes enjoy humor that disparages others, but there is little evidence that such vicarious hostility reduces our aggressive urges.

\section{Superiority Theory}

Superiority theory dates back to the earliest Greek philosophers. Both Plato and Aristotle posited that people find the weaknesses of others humorous, and that "laughter is an expression of derision or malice directed at the less fortunate" (Ferguson \& Ford, 2008, p. 288).

Many centuries later, Thomas Hobbes, who is often considered the "father" of modern humor theory, hypothesized that amusement and laughter are the result of the glory we feel when we favorably compare ourselves with less fortunate others (Hobbes, 1651/1968). Hobbes noted "It is no wonder therefore that men take heinously to be laughed at or derided, that is, triumphed over" (Hobbes, 1681/1968).

Charles Gruner (1997) is a modern advocate of the superiority theory of humor. He proposes that all humor, no matter how seemingly innocuous, contains hostility and aggression. This perspective would seem at odds with the existence of humor that appears nonaggressive. For example, puns and limericks often use clever wordplay to amuse. Or humor can be used to poke fun at oneself, or to comment on the absurdities of life. Yet Gruner maintains that aggression tow ard others and triumphing over them is an essential aspect of humor, at least implicitly: "Successful humor... must include winning" (1997, p. 9).

The concept of shadenfreude (delight in the misery of others) captures the essence of this superiority dynamic - it sometimes makes us feel good to see other people fail. Ridicule simply adds a dose of humor to the mix, thus making our shadenfreude more socially acceptable. A humorous communication implies that its message is to be interpreted in a non-serious manner. Thus, "disparagement humor can uniquely 
denigrate its target while stifling challenge or criticism" (Ferguson \& Ford, 2008, p. 284). One theme of our own research, described later in this article, is that shadenfreude can be a double-edged sword, so to speak: when we revel in the misery of others, we may also become more acutely aw are that others may similarly revel in our misery.

\section{Disposition Theory}

A more recent version of superiority theory, disposition theory, echoes the basic premise that we are entertained by the misfortunes of others, but also stipulates that our relationship to the target of the humor affects the degree of our enjoyment of the humor. Specifically, we are more entertained by the disparagement of targets we dislike or members of an out-group, as opposed to targets we like or members of our in-group (e.g., La Fave, 1972; Wicker, Baron, \& Willis, 1980). For example, in an early experiment on humor, Wolff, Smith, and Murray (1934) presented anti-Jewish jokes to both Jewish and non-Jewish participants. Perhaps not surprisingly, they found that the non-Jewish participants enjoyed the jokes more than the Jewish participants.

Zillmann and Cantor (1976) emphasized the importance of an individual's attitudes toward the target group, rather than merely in-group vs. out-group status, in determining one's appreciation for humor that targets an out-group. For example, Thomas and Esses (2004) found that men who were high in hostile sexism reported more enjoyment of jokes that disparaged females compared to men who were low on this dimension.

As noted earlier, one way in which ridicule can be distinguished from disparage ment humor is that the former is more personal in nature and is usually directed at an individual rather than a group (Wilson, 1979). For example, ridicule often consists of derisive joking about some aspect of an individual's behavior or appearance. An interesting study that examined personal attitudes toward a particular individual was conducted by Zillmann and Bryant (1980). In this study, participants were treated either rudely or politely by a female experimenter. Participants then witnessed her in one of three conditions: she spilled a cup of hot tea on herself; she spilled tea on herself when a jack-in-the-box suddenly popped out of a box; or a jack-in-the-box popped up, but she did not spill her tea. Results of the study indicated that humor cues (smiling and laughing) were highest in the condition in which the participants had been treated rudely by the experimenter and the tea was spilled in response to the jack-in-the-box. It appeared, therefore, that observing a disliked target have a 
mishap was not sufficient for the experience of mirth: some humorous cues were also necessary.

Social I dentity Theory

Social identity theory (Tajfel, 1978; Tajfel \& Turner, 1986) is a broad perspective built on the assumption that people's group memberships constitute an important part of their identity. Whereas traditional models of identity focus on individuals' personal qualities and accomplishments (Baumeister, 1998), social identity theory emphasizes individuals' social relationships and group memberships as additional sources of selfevaluation.

Social identity theory assumes that people want to maintain a positive identity, including a positive social identity. One way to achieve a positive social identity is by judging one's own groups to be superior to other groups. In fact, researchers have found that individuals will try to create a positive social identity by treating members of in-groups more favorably than me mbers of out-groups (e.g., Tajfel, 1970).

Clearly, a motivation to perceive one's in-groups as superior to out-groups can be served by disparaging humor about those out-groups. Thus, social identity theory provides a motivational account of why people enjoy disparagement humor (Bourhis, R.Y., Nicholas, J.G., Howard, G., \& Henri, T. 1977; Ferguson \& Ford, 2008). For example, evidence that members of ethnic groups find humor about other ethnic groups funnier than humor about their own ethnic group (e.g., La Fave, 1972; Wicker et al., 1980; Wolff et al., 1934) may reflect perceivers' desires to create or maintain a positive social identity.

The Effects of Disparagement Humor on Attitudes and behavior

Given the prevalence of disparagement humor in our culture, understanding its effects on listeners' attitudes and behavior is important. There is a common perception that disparagement humor can influence listeners' stereotypes; that is, hearing disparaging jokes targeting a particular group may strengthen or perhaps even create negative stereotypes about that group. A series of experiments by Olson, Maio, and Hobden (1999) tested this perception. In their studies, participants were exposed to disparaging humor about men or about lawyers, whereas control groups were exposed to non-disparaging humor, non-humorous disparagement, or nothing. Participants' attitudes towards the target groups were then assessed, as well as the latencies of responses to these attitude items (as an indication of the 
accessibility, or ease of retrieval, of the attitudes). Additionally, participants were asked to rate the target groups on stereotypic attributes and to evaluate ambiguous behaviors by members of the target group.

The results suggested that exposure to disparaging humor did not influence participants' attitudes toward members of the target group, nor did it elicit stereotypical attributions regarding the group. One important limitation of these studies, as the authors noted, was that the targets of the disparagement humor were relatively high-status individuals (lawyers). Perhaps the effects of exposure to disparagement humor would be more pronounced with socially marginalized groups.

A subsequent experiment asked participants to recite, as opposed to listen to, disparaging humor about another target group (Newfoundlanders-people living in a Canadian province who are sometimes negatively stereotyped). Results showed that participants who had recited the humor expressed more negative stereotypes about Newfoundlanders than did those who recited non-disparaging humor (Maio, Olson, \& Bush, 1997). The authors noted that these findings could be explained by either cognitive dissonance theory or self-perception theory. According to cognitive dissonance theory (Festinger, 1957), the participants' negative behavior (reciting the disparaging jokes) may have conflicted with their actual, positive attitudes toward the target group, which elicited dissonance arousal and led them to alter their opinions to be more consistent with their negative behavior. Alternatively, according to self-perception theory (Bem, 1967), participants may have been unsure of their original attitudes toward the target group. Reciting disparaging jokes about that group may have led participants to infer that their attitudes were relativ ely negative.

Prejudiced Norm Theory

A relatively recent theory that has attempted to delineate more clearly the mechanisms through which disparagement humor can affect people's attitudes is prejudiced norm theory (Ford \& Ferguson, 2004). These researchers have focused on whether disparaging humor targeting an out-group increases tolerance for discrimination toward members of those groups. According to Ford and Ferguson, disparaging humor makes prejudice and discrimination toward the target group more acceptable; it contains a "normative standard that, in this context, one need not consider discrimination against the targeted group in a serious or critical manner" (p. 83). As a result, individuals who are already predisposed to feel 
negatively toward the target group are likely to exhibit increased tolerance for discrimination. For example, Ford et al. (2001) found that men who scored high in

hostile sexism were more likely than men low in this dimension to perceive a norm of tolerance to sexism upon exposure to sexist humor. Exposure to non-humorous sexist statements, or to non-sexist humor, did not produce this tolerance. It appears that the levity contained in humor allows those who are predisposed to feel negatively about particular groups to bypass critical assessment of the derogatory information embedded in the humor.

Ridicule as an Educational Corrective

Some researchers have also examined whether ridicule may be used an educational corrective-to encourage positive behaviors through the ridicule of negative behaviors. For example, an experiment by Bryant, Brown, Parks, and Zillmann (1983) had young children observe muppet models being corrected for engaging in specific negative behaviors through either ridicule, commands, or suggestions. Later, the children were observed to see whether they engaged in the targeted negative behaviors. Interestingly, 6-year olds were more influenced by the ridicule than the other modes of correction, whereas 4 -year olds were not. The authors hypothesized that "6-year olds are apparently sufficiently socialized to recognize and appreciate the punishing power of derisive laughter. In contrast, 4year olds... may lack the experience necessary to recognize derision for what it is" (Bryant et al., 1983, p. 252).

Another study examining the use of ridicule as an educational corrective was conducted with university students (Bryant, Brown, \& Parks, 1981). Students in a lecture-style course were given one of three course handouts employing different motivational strategies. In one condition, the handout consisted of cartoons ridiculing students who did not complete their course readings. Other students were given handouts insulting (without humor) students who did not complete the readings. A third group of students was assigned to a "gentle reminder" condition, with a message stressing the importance of completing the course readings. The dependent measure in this study was the performance of the students on a surprise quiz that tested knowledge of the course readings. Students in the ridicule condition performed significantly better on the quiz than did students in the other two conditions. 
An interesting aspect of these results is the finding that ridicule was more effective than insult in motivating the students. There are at least two possible reasons why, in various settings, ridicule may have more impact than insult. First, ridicule makes retaliation (e.g., rejection of the attempted influence in the course outline) less appropriate for the target. Unlike insult, which can only be interpreted as aggressive, ridicule contains an element of levity or amusement. Targets might hesitate to engage in retaliation to ridicule because they do not want to be seen as "a poor sport" or "having no sense of humor." Second, ridicule is more socially acceptable than insult. A person (e.g., a professor) who ridicules others (e.g., in the course outline) may be perceived as witty and clever, possessing a good sense of humor, whereas someone who insults others is more likely to be perceived as rude or boorish. These perceptions are likely to increase the persuasiveness and influence of the former individual relative to the latter.

Self-Deprecating Humor

Self-deprecating humor occurs when an individual pokes fun at him or herself. Whereas humor that ridicules other people has been shown to have potentially negative effects (e.g., greater tolerance of discrimination against the targeted group), it seems plausible that self-deprecating humor might have different consequences. For example, observing another person making light of her or her personal shortcomings may induce liking for the apparently modest speaker, which might prevent the attribution of negative characteristics to him or her. Indeed, by joking about personal weaknesses or failures, a self-deprecating model demonstrates a lack of concern about the social consequences of the admitted foibles. This lack of concern may encourage observers to perceive their own shortcomings as less serious or even amusing.

Unfortunately, research examining self-deprecating humor is relatively scarce and has not directly tested the preceding speculations. An early study conducted by Stocking and Zillmann (1976) found that a male who disparaged himself was perceived by other men as having lower self-esteem, being less intelligent, and being less confident than a male who disparaged others. Women, on the other hand, reported more favourable impressions of those males who engaged in selfridicule.

A more recent study by Lundy, Tam, and Cunningham (1998) examined the combined effects of self-deprecating humor and physical attractiveness on an observer's desire for future romantic interactions. Male and female participants were 
shown a photograph of a person of the opposite sex and a transcript of an interview with that person. The independent variables were whether the photograph was of an attractive or unattractive person, and whether the transcript contained selfdeprecating humor or no humor. Participants expressed their interest in several types of relationships with the target person (e.g., dating, marriage, intercourse).

For men, the attractive female target was perceived to be more desirable than the unattractive female target for most types of relationships, and humor had no effects. For women, however, there was an interaction between attractiveness and humor. Self-deprecating humor increased the desirability of attractive males, but not of unattractive males. This increased desirability was found for both short term (e.g., intercourse) and long-term (e.g., marriage) relationships. Unfortunately, because this study did not include targets who exhibited other-deprecating ridicule, it is impossible to ascertain whether females' greater liking for attractive males who used self-deprecating humor was due to the self-deprecating nature of the humor or to the simple fact that the males exhibited a sense of humor of any kind.

A study by Greengross and Miller (2008), examining the adaptive functions of humor, did contrast the effects of self- and other-deprecating humor. Participants listened to tape recordings of opposite-sex people who generated either self-deprecating or other-deprecating humor, and who were described as either high or low status. Participants were asked to rate the target's attractiveness as a short- and long-term mate. Humor style and status had no effect on short-term attractiveness of the target, but both men and women rated high-status presenters who engaged in selfdeprecating humor as being more attractive as long-term mates than those who engaged in other-deprecating humor, No differences were found in the low-status condition. These studies suggest that individuals who are socially advantaged (e.g., high status, attractive) might be perceived as more appealing when they engage in self-deprecating humor, perhaps because this type of humor signals a sense of modesty on the part of the humorist that would bode well for long-term relationships.

\section{Humor Styles}

Another issue that is relevant to understanding both other-ridicule and selfdeprecating humor is the notion of preferred humor styles. The Humor Styles Questionnaire, developed by Martin, Puhlik-Doris, Larsen, Gray, and Weir (2003), was designed to assess chronic individual differences in preferred types of humor. The authors proposed that there are four principal types of humor: aggressive, affiliative, self-defeating, and self-enhancing. Martin et al. hypothesized that aggressive and 
self-defeating humor are relatively unhealthy and maladaptive, whereas affiliative and self-enhancing humor are more healthy and adaptive.

Aggressive humor is the tendency to use humor to demean others; most ridicule directed at other people falls into this domain. Affiliative humor refers to the tendency to be humorous in order to amuse others. This type of humor represents a non-hostile, tolerant use of humor that enhances interpersonal relations. Whereas ridicule of others would generally fall into the category of aggressive humor, sometimes people in close relationships will lovingly tease each other, poking fun at the other person's weaknesses. In this case, the humor is intended more for affiliative purposes than aggressive ones. Thus, it may be difficult at times to distinguish between aggressive and affiliative styles of humor. A key distinction, however, between the two styles is that affiliative humor is associated with concern and care about others, whereas aggressive humor is characterized by "lack of personal regard or concern for the feelings and rights of others" (Kuiper, Grimshaw, Leite, \& Kirsh, 2004, p.145).

Self-enhancing humor refers to humor that allows the speaker to maintain a positive and amused perspective on life's trials and tribulations. Self-defeating humor, on the other hand, refers to the use of excessively self-disparaging humor, perhaps to ingratiate oneself with others. The boundaries between self-enhancing and selfdefeating humor can be blurred as well. They are both self-focused in orientation, as opposed to the other-orientation of affiliative and aggressive humor (Kuiper et al., 2004). Although the use of self-deprecating humor might be excessive in some cases (and therefore qualify as self-defeating humor), at other times, it is more moderate and constitutes self-enhancing humor-laughing at one's own difficulties. For example, in the opening scene of An Inconvenient Truth, Al Gore announces "Hello, my name is Al Gore, and I used to be the next president of the United States". The crowd ate it up. Although self-deprecating, this type of humor can be considered self-enhancing. Allport (1950) noted that "the neurotic who learns to laugh at himself may be on the way to self-management, perhaps to cure" (p. 180). When engaging in self-de precation, we take ourselves less seriously, something that may be adaptive rather than self-defeating. At times self-deprecation may actually be liberating, allowing us to reinterpret negative stereotypes in a positive way. In his article exploring Jewish self-deprecating humor, Davies noted that "ethnic jokes told from outside as mockery can become assertions of autonomy and vitality when told be the subjects themselves" (1991, p.189). 
Thus, both other-directed and self-deprecating humor come in different varieties. People may poke fun at others in gentle ways that promote affiliation, or they can engage in more hostile other-ridicule. Similarly, people may mock themselves in gentle ways that remind the audience that everyone has weaknesses and foibles, or they can exhibit more extreme self-ridicule, perhaps in a desperate attempt to be liked by others.

Armed with this brief review of research on disparagement humor, we can now turn to the specific issue that has driven our own research. We have been interested in the effects of observing ridicule, either other-directed or self-directed, on individuals' psychological states and behavioral tendencies. Our specific hypotheses concern the possible differential effects of other-directed versus self-directed ridicule on conformity, fear of failure, and creativity. We coined the term "jeer pressure" to capture the essence of the process that results from observing other-directed ridicule.

\section{Research on Jeer Pressure}

In our research, we have tested the hypothesis that observing another person being ridiculed has an inhibiting effect on the observer. This jeer pressure (similar to "peer pressure") is assumed to spring from evaluation apprehension-a concern on the part of the observer that he or she might also become a target of evaluation and ridicule. The evaluation apprehension motivates conformity: the individual will conform to norms and rules so as to avoid standing out. Jeer pressure was also expected to reduce participants' creativity, which requires divergent thinking. We have also tested a secondary hypothesis, which is that self-ridicule, rather than producing inhibition and conformity, might actually have a disinhibiting effect. We speculated that seeing an individual make fun of him or herself might make the observer less concerned than usual about being negatively evaluated and, therefore, less conforming and more creative.

\section{Overview of Dependent Measures in Studies}

The dependent measures we employed in one or more of our three experiments were: conformity, fear of failure, and creativity. First, we expected that seeing another person being ridiculed would produce conformity in the observer, because he or she would want to reduce the likelihood of personally becoming a target of ridicule. In fact, several theorists have suggested that one of the social functions of ridicule is to castigate nonconformity (e.g., Martineau, 1972; Wilson, 1979). 
Conformity was assessed in Experiments 1 and 2 by having participants rate the funniness of four cartoon strips, which had bogus ratings by "previous participants" included on the rating sheet (ostensibly to save trees by conserving paper). These "previous ratings" were designed to be erroneous: the funniest cartoons received the lowest bogus ratings, whereas the least funny cartoons received the highest bogus ratings. Confor mity was defined as adhering closely to the "previous ratings".

A second dependent measure in Experiments 1 and 2 was fear of failure. We predicted that observing another person being ridiculed would increase participants' fear of failure on a subsequent task because they would be more anxio us about being ridiculed if they failed. We assessed fear of failure via a ring toss task, in which participants tried to throw rings made of rope onto wooden pegs. According to early research conducted by Atkinson and Litwin (1960), people who are afraid of failing on this task are more likely to employ either a self-handicapping strategy (whereby they stand very far away from the peg to toss the rings, giving themselves a plausible explanation for failure) or a low risk strategy (whereby they minimize the chances of failing by standing very near to the peg to toss the rings). In contrast, individuals who are lower in fear of failure are more likely to stand at a moderate distance from the peg to toss the rings; in this fashion, they are able to realistically challenge themselves at the ring toss task.

Finally, in all three studies, we measured creativity, which we also expected to be influenced by observing the ridicule of others. Because creativity involves divergent thinking -thinking "outside the box"-it was assumed that observing others being ridiculed might constrain this type of thinking. The desire to avoid looking foolish might interfere with one's ability or motivation to engage in unconventional thinking. Thus, observers of other people being ridiculed were expected to exhibit less creative thinking than those who did not witness such ridicule. In contrast, observers of self-ridicule were expected to feel more comfortable taking risks and, therefore, to exhibit greater creativity. Creativity was assessed in Experiments 1 and 2 using the Multiple Uses Task (Torrance, 1962), in which participants are asked to generate as many non-traditional uses for a brick as possible. Responses are scored for both quantity and creativity (non-traditional responses). A different task was used to measure creativity in Experiment 3, which we will describe later.

\section{Experiment 1}

In Experiment 1 (Janes \& Olson, 2000, Experiment 1), participants were exposed to one of three 8-min videotapes of a stand-up comedian telling jokes. In the other- 
ridicule condition, the comedian told ridiculing jokes about another person. In the self-ridicule condition, the comedian told the same jokes, but with himself as the target (e.g., "This guy I know tried to join a lonely hearts club, but they said 'Hey, we're not that desperate'" vs. "I tried to join a lonely hearts club, but they said "Hey, we're not that desperate'"). In the control condition, the humor had no target (e.g., "He crossed a hyena with a parrot so it could tell him what it was laughing about"). After observing one of the humorous videotapes, participants completed the fear of failure, conformity, and creativity tasks.

Results. Analyses showed that participants who viewed the other-ridiculing videotape exhibited more fear of failure than participants in the other two conditions. Specifically, in the ring toss task, participants who viewed other-ridicule were more likely to stand either very close to the peg (indicating a lack of selfchallenge) or very far from the peg (indicating self-handicapping) than participants in the self-ridicule and control conditions, who did not differ and who stood a more moderate distance from the peg, indic ating that they were realistically challenging the mselves (Atkinson \& Litwin, 1960).

Participants in the other-ridicule condition also exhibited more conformity than participants in the other two conditions. Specifically, participants who viewed otherridicule were more likely to match the bogus funniness ratings of the cartoons than were participants in the self-ridicule and control conditions, who did not differ.

No differences between conditions were found, however, on the creativity task. Thus, other-ridicule did not impair creativity.

Surprisingly (at least to us), on all three dependent measures, no significant differences emerged between the self-ridicule condition and the control condition. Thus, self-deprecating humor did not appear to have any disinhibiting effects on participants' behavior or thinking.

\section{Experiment 2}

The second experiment (Janes \& Olson, 2000, Experiment 2) was designed to replicate Experiment 1 and to investigate a possible mediator of the obtained effects of other-ridicule. Our conceptual reasoning was that the effects of observing other people being ridiculed were caused by an increased salience of potential personal rejection; that is, observing another person being ridiculed increased the accessibility of the observer's thoughts about his or her own possible ridicule or 
rejection. We assessed this hypothesized salience of rejection using a lexical decision task. Participants had to decide, as quickly and accurately as possible, whether a string of letters displayed on a computer screen comprised a word or a non-word. Forty trials involved real words: 10 acceptance-related words (e.g., accepted, approval), 10 rejection-related words (e.g., humiliated, mocked), and 20 neutral words. There were also 40 non-word filler trials. If, indeed, observing other-ridicule increases the accessibility of rejection-related thoughts, then such participants should recognize rejection-related words more quickly (and perhaps acceptancerelated words more slowly) than participants in other conditions.

Experiment 2 employed the same basic design as Experiment 1. Participants viewed one of three 8-min videotapes and then completed the dependent measures. New versions of the videotapes, however, were developed for this second study. These videos were ostensibly designed to be educational videos-teaching observers how to change a bicycle tire. On these videos, an instructor and his assistant gave instructions regarding the lesson. In the self-ridicule condition, the instructor made several mistakes throughout the video and expressed ridiculing comments about himself. In the other-ridicule condition, the instructor again made mistakes, but his assistant directed the ridiculing comments at the instructor. Thus, the ridiculing comments were identical in the two conditions, but they were delivered either by the instructor or by the assistant. For example, at one point in the lesson, the instructor pinched his finger in a pump while trying to inflate one of the bicycle's tires; he or the assistant then said "I guess that's why they call it a foot pump!" In the control condition, no ridiculing comments were made by either person in the videotape. The dependent variables included the same measures of fear of failure and creativity that were used in Experiment 1, as well as the lexical decision task. The conformity measure was changed slightly: participants rated qualities of the videotape itself rather than funniness ratings of cartoons, but the logic of the measure was the same (i.e., inaccurate ratings by alleged "previous participants" were provided).

Results. Replicating Experiment 1, the analyses showed that participants in the otherridicule condition exhibited greater fear of failure on the ring-toss task and greater conformity in the cartoon-rating task than did participants in the other two conditions, who did not differ from one another. Thus, again, the self-ridicule condition did not have a disinhibiting effect compared to the control condition. Also replicating the first study, no differences between any of the three conditions were found on the creativity measure. 
Importantly, the lexical decision task also yielded significant differences between conditions. As predicted, participants in the other-ridicule condition recognized rejection-related words (relative to neutral words) signific antly more quickly than did participants in the self-ridicule and control conditions, who did not differ. Thus, exposure to other-ridicule made thoughts of rejection more accessible. No differences between conditions were revealed in responses to the acceptancerelated words. We also conducted mediation analyses that tested whether thoughts about rejection mediated the effects of other-ridicule on fear of failure and conformity. These analyses indicated that the salience of rejection (as evidenced by faster responses to rejection-related words than to neutral words) did, indeed, mediate the effect of other-ridicule on fear of failure; that is, when responses on the lexical decision task were controlled statistically, the other-ridicule condition did not differ from the remaining conditions in fear of failure. In contrast, the salience of rejection did not mediate the effect of other-ridicule on conformity. Perhaps our measure of conformity reflected a wish not to stand out, rather than fear of rejection perse.

In sum, the results of the first two experiments supported our primary hypothesis that observing other people being ridiculed would have an inhibiting effect on the observer. In both experiments, participants in the other-ridicule condition exhibited more fear of failure and more conformity than participants in the self-ridicule and control conditions. Additionally, evidence in Experiment 2 implicated the accessibility of thoughts about rejection as the psychological mediator of the differences in fear of failure.

We think it is noteworthy that inhibiting effects were obtained in response to the videotapes used in these studies, given the non-threatening nature of these stimulus materials. Participants observed other-ridicule via a stand-up comedian or an educational tape demonstrating how to change a bicycle tire. There was no possibility that participants would be ridiculed by these individuals: the ridicule was pre-recorded, and participants did not expect to meet the depicted individuals. If these kinds of distant, non-threatening exposures to other-ridicule can produce jeer pressure, imagine what people must feel in real-life situations where they are exposed to actual ridicule and might, indeed, become a target of ridicule the mselves (e.g., in the schoolyard or at social gatherings).

Neither experiment found differences in creativity due to the humor stimuli. One possible explanation for these null results is that the Multiple Uses Task (Torrance, 1962) has been criticized for relying excessively on verbal fluency as opposed to 
creativity. Additionally, in both studies the creativity measure was assessed last, after the fear of failure and conformity measures. It is possible that any effects had dissipated by the time the third dependent variable was assessed. In Experiment 3, we employed a different measure of creativity, and creativity was the sole variable we assessed.

Also, neither experiment showed significant effects for self-deprecating humor compared to the control groups. That is, self-ridicule did not have its predicted disinhibiting effects, such as increasing individuals' creativity. One possible explanation for these null results may be that the ridiculing jokes contained on the videotapes were too hostile or extreme, so when they were told as self-ridicule, they fell into the self-defeating category rather than the self-enhancing category (Martin et al., 2003). In the next experiment, we employed jokes that were gentler and more self-enhancing in nature, hoping that they might produce the predicted disinhibiting effect on observers.

\section{Experiment 3}

In a third experiment (Janes \& Olson, 2009), only creativity was assessed. We focused on this variable because ridicule's effects on fear of failure and conformity had already been replicated in the previous studies. We expected that other-ridiculing humor would hinder creativity in participants, given the "inhibiting" effect that this ridicule had on participants in term of conformity and fear of failure. Moreover, some research suggests that environmental cues associated with danger activate in people a systematic, detail-oriented, risk-averse processing style, whereas a benign environment motivates a "risky processing style, in which internal knowledge structures serve to enrich the information at hand, thereby leading to more unconstrained creative thinking and a broad conceptual scope" (Kuschel, Förster, \& Denzler, 2010, p. 4). It seemed possible that observing ridicule of other people might be perceived as danger-related, whereas observing someone poking fun at themselves would produce a more benign environment (and, therefore, unconstrained creative thinking).

In this study, participants were again exposed to one of three videotapes containing either self-ridicule, other ridicule, or no humor. Participants were led to believe that they were watching an instructional videotape offering a 10-min lesson on writing Haiku poetry (a highly stylized form of Japanese poetry) by a professor. As in the first two studies, the only difference between the conditions related to humor. In the selfridicule condition, the professor poked fun at himself (e.g., "My idea of roughing it is 
getting poor service at the Holiday Inn."), whereas in the other-ridicule condition, the professor made fun of someone else (e.g., "His idea of roughing it is getting poor service at the Holiday Inn."). These ridiculing jokes/comments were selected to be less caustic and denigrating than in the prior studies. In the control condition, all humorous comments were omitted.

Participants watched one of the three videos, ostensibly to learn how to write Haiku poetry, and were told that their comprehension of the material would be assessed. After watching the videotape, students reported their impressions of the instructor on a series of 7-point scales (e.g., "The instructor on the videotape seemed warm and friendly"). Next, participants completed a creativity task, Torrance's Test of Creative Thinking (1966), which involved using circles to make more elaborate objects. The validity of this test as a measure of creativity has been empirically supported (e.g., Torrance \& Perbury, 1984; Torrance \& Safter, 1989); scores reflect four dimensions of creativity: originality, fluency, flexibility, and elaboration.

Results. Analyses revealed a main effect for humor condition on participants' creativity scores. As predicted, participants in the self-deprecating condition exhibited significantly higher levels of creativity on the task than did participants in the other-ridicule and no-ridicule conditions, which did not differ. Additionally, participants' perceptions of the instructor on the videotape were more positive in the self-ridicule condition than in the other two conditions, which again did not differ. Specifically, participants in the self-ridicule condition found the instructor to be significantly more "warm" than did participants in the other two conditions and expressed signific antly higher levels of respect for the instructor than did participants in the other two conditions.

To our knowledge, this study provides the first empirical evidence that selfdeprecating humor can have positive, disinhibiting effects relative to a control condition; participants in the self-ridicule condition were more creative than participants in the other two conditions. Creativity requires divergent thinking-that is, approaching a task with an open and curious mind. It makes sense that exposure to someone who pokes fun at his or her own weaknesses and foibles can produce greater openness and creativity. Presumably, self-deprecating humor generated a non-threatening atmosphere that allowed participants to be more "daring" in their thoughts about the task.

There are at least three possible explanations for why the first two studies examining self-ridicule did not find any differences in creativity between conditions, whereas 
Experiment 3 did. First, the dependent measure for creativity in Experiment 3 (Torrance Test of Creativity) was arguably a better measure than the one used in the first two studies (Multiple Uses Task), which has been criticized for tapping verbal fluency rather than divergent thinking. Second, in Experiment 3, the creativity task was administered very soon after the videotape (with only the ratings of the instructor intervening); this procedure ensured that the effects of observing the humor had not dissipated by the time the participants performed the creativity task. Finally, the nature of the humor employed in the studies differed. In the first two studies, the self-deprecating humor (and the other-ridiculing humor) was quite caustic (e.g., "When I was a kid, I was so unpopular that my mother had to tie a pork chop around my neck just to get the dog to play with me"). In the third experiment, the ridicule was gentler and less dehumanizing (e.g., joking that someone's idea of roughing it is getting poor service at the Holiday Inn). In this context, we should note that the gentler nature of the ridicule in Experiment 3 might also have contributed to the null result that participants in the other-ridicule condition were not creatively inhibited (although reduced creativity was also not obtained in the first two experiments).

Another finding in Experiment 3 was that perceptions of the instructor in the selfridicule condition were more positive than those in the other conditions. The selfdeprecating instructor was perceived to be more "warm" than the instructors in the other two conditions, and participants had more respect for the self-deprecating instructor. The latter effect-greater respect for the self-deprecating instructor than for the other-ridiculing instructor-conflicts with early research examining perceptions of the instigators of ridicule. For example, in the research cited earlier by Stocking and Zillmann (1976), it was found that a male who disparaged himself was seen as having lower self-esteem, being less intelligent, and being less confident than a male who disparaged others-though only by male perceivers, not female perceivers. More recent research suggests that both men and women favor opposite-sex individuals who generate self-deprecating as opposed to other deprecating humor for long-term relationships, providing they are high status (Greengross \& Miller, 2008). Perhaps changes over the last three decades in norms and sex-role stereotypes have resulted in more favorable attitudes tow ard those who poke fun at themselves and less favorable attitudes toward those who ridicule other people among both men and women. 


\section{General Discussion}

Whereas much research has examined humor, very little has investigated the psychologic al and behavioral effects of observing different types of humor. To our knowledge, with one exception (Stocking \& Zillmann, 1976), the present research is unique in that it contrasts other-deprecating and self-deprecating ridicule while holding the content of the jokes constant. This design makes it possible to ascertain that the target of ridicule, regardless of the content, is critical for how that ridicule affects observers.

Our research documents two, contrasting effects of ridicule. First, observing ridicule of others has inhibiting effects-it motivates people to be "wary" in their behavior. The thought of being the target of ridicule oneself is aversive enough to inhibit people from standing out (e.g., they conform to the perceived opinions of others). Although this fear of ridicule can be employed in socially useful ways (e.g., the research described earlier on ridicule as an educational corrective), ridicule is often used for less socially desirable purposes. For example, school-aged children and teenagers are often subjected to ridicule for failing to conform to peers' standards of behavior. The student who refuses to take drugs or drink alcohol may be ridiculed, as may an individual whose interests or clothes do not conform to those preferred by the peer group.

Of course, these last examples involve the direct targets of ridicule, and our studies show that the effect of ridicule goes beyond the target. Our research shows that those who merely observe others being ridiculed are affected by it-even when they are in no danger of being the target of ridicule themselves. Witnessing another person being ridiculed leads observers to avoid behavior that might stand out; they choose, instead, to "play it safe". The fear of being noticed and/or performing badly in front of others can result in missed opportunities (e.g., participants in Experiments 1 and 2 did not realistically test the mselves on the ring-toss task).

Ridicule is not confined to the schoolyard by any means. Election campaigns seem to be increasingly characterized by ridicule and less by open discussion of the issues involved. An interesting, though unanswerable, question is how many competent and responsible individuals have been deterred from seeking public office due to fear of personal ridicule. As Mark Twain noted, "There is no character, howsoever good and fine, but it can be destroyed by ridicule, howsoever poor and witless" (1893). 
The second effect of ridicule documented in our research involves self-deprecating humor, which appears to have disinhibiting effects. With this type of humor, the individual makes jokes about his or her own personal shortcomings. Often, selfdeprecating humor involves poking fun at those "absurdities and infirmities" that beset all of us. Our final study showed that merely observing self-deprecating humor can produce greater creativity-it seems to induce a readiness and/or ability to engage in more divergent thinking, presumably because people are more willing to risk generating ideas that might be perceived as bizarre or outlandish.

\section{Limitations}

There are some potential limitations to our research on the effects of both self- and other-directed ridicule that should be noted. The first limitation relates to individual differences. It is likely that there are traits that influence how people are affected by various types of humor. For example, individuals' chronic humor styles may influence their responses to observing ridicule. An individual who tends to use hostile humor in interpersonal settings may be less influenced by observing ridicule of others than an individual who refrains from that type of humor, whereas an individual who tends to use affiliative humor might be more disinhibited by self-ridicule than an individual who refrains from that type of humor.

Additionally, the theme or topic of the humor may influence how people are affected by it. For example, observing other-directed ridicule that mocks characteristics that the observer feels he or she also possesses may have greater impact than ridicule mocking a characteristic that the observer considers personally irrelevant. Thus, an athletically-challenged individual may be more inhibited by observing other-directed ridicule that targets another person's lack of athletic prowess than would a varsity athlete. The inhibiting effects of observing ridicule of others may be more potent when the observer feels potentially vulnerable as a target of the ridicule content.

\section{Concluding Comment}

The scientific study of humor is an important endeavor. Humor is one characteristic that distinguishes humankind from other species, and humor is ubiquitous in daily life. Humans laugh from an early age and, moreover, like to laugh. Humans do not, however, like to be laughed at. These conflicting responses account for the complex effects of ridicule. We hope that our work will contribute to a fuller understanding of the behavioral and psychologic al consequences of other-ridicule and self-ridicule. 


\section{References}

Allport (1950). The individual and his religion. New York; Macmillan.

Atkinson, J.W. \& Litwin, G.H. (1960). Achievement motive and test anxiety conceived as motive to approach success and motive to avoid failure. Journal of Abnormal and Social Psychology, 60, 52-63.

Baron, R. A. (1978). The influence of hostile and nonhostile humor upon physical aggression. Personality and Social Psychology Bulletin, 4, 77-80.

Baumeister, R.F. (1998). The self. In D.T. Gilbert, S.T. Fiske, \& G. Lindzey (Eds), Handbook of Social Psychology (4th ed. Pp. 680-740). New York: McGraw Hill.

Bem, D.J. (1967). Self-perception: An alternative interpretation of cognitive dissonance phenomena. Psychological Review, 74, 183-200.

Bourhis, R.Y., Nicholas, J.G., Howard, G., \& Henri, T. (1977). Context and ethnic humor in intergroup relations. In A.J. Chapman \& H.C. Foot (Eds.), It's a funny thing, humor. (pp. 261-265). Elmsford, NY: Pergamon.

Bryant, J., Brown, D., Parks, S.L., (1981). Ridicule as an educational corrective. Journal of Educational Psychology, 73, 722-727.

Bryant, J., Brown, D., Parks, S.L., \& Zillmann, D. (1983). Children's imitation of a ridiculed model. Human Communication Research, 10, 243-255.

Davies, C. (1991). Exploring the thesis of the self-deprecting Jewish sense of humor. Humor: International Journal of Humor Research, 4, 189-209.

Ford, T.E. \& Ferguson, M. A. (2004). Social consequences of disparagement humor: A prejudiced norm theory. Personality and Social Psychology Review, 8, 79-94.

Ford, T.E., Wentzel, E.R., \& Lorion, J. (2001). Effects of exposure to sexist humor on perceptions of normative tolerance of sexism. European Journal of Social Psychology, $31,677-691$.

Ferguson, M.A. \& Ford, T.E. (2008). Disparagement humor: A theoretical and empirical review of psychoanalytic, superiority, and social identity theories. Humor: International Journal of Humor Research, 21, 283-312. 
Festinger, L. (1957). A theory of cognitive dissonance. Syanford: CA, Stanford University Press.

Freud, S. (1960). Jokes and their relation to the unconscious. (James Strachey, Trans.). New York: Norton.

Gruner, C.R. (1978). Understanding laughter: The workings of wit and humor. Chicago: Nelson-Hall.

Gruner, C.R. (1997). The game of humor: A comprehensive theory of why we laugh. New Brunswick, NJ: Transaction Publishers.

Hobbes, T. (1968). Leviathan. Harmonsworth: Penguin. (Originally published 1651).

Janes, L.M. \& Olson, J.M. (2000). Jeer pressure: The behavioral effects of observing ridicule of others. Personality and Social Psychology Bulletin, 26, 474-485.

Koestler, A. (1964). The act of creation. London: Hutchinson.

Kuiper, N.A., Grimshaw, M., Leite, C., \& Kirsh, G. (2004). Humor is not always the best medicine: Specific components of sense of humor and psychological well-being. Humor: International Journal of Humor Research, 17, 135-168.

Kuschel, S., Förster, J., \& Denzler, M. (2010). Going beyond information given: How approach versus avoidance cues influence access to higher order information. Social Psychological \& Personality Science, 1, 4-11.

La Fave, L. (1972). Humor judgments as a function of reference groups and identification classes. In J. H. Goldstein \& P.E. McGhee (eds.), The Psychology of Humor (pp. 195-210). NY: Academic Press.

Lundy, D.E., Tan, J., \& Cunningham, M.R. (1998) Heterosexual romantic preferences: The importance of humor and physical attractiveness for different types of relationships. Personal Relationships, 5, 311-325.

Maio, G.R., Olson, J.M. \& Bush, J. (1997). Telling jokes that disparage social groups: Effects on the joke-teller's stereotypes. Journal of Applied Social Psychology, 27, 1986-2000.

Martin, R.A. (2007). The psychology of humor: An integrative approach. Amsterdam: Elsevier. 
Martin, R.A., Puhlik-Doris, P., Larsen, G., Gray, J., \& Weir, K. (2003). Individual differences in uses of humor and their relation to psychological well-being: Development of the Humor Styles Questionnaire. Journal of Research in Personality, 37, 48-75.

Martineau, W.H. (1972). A model of the social functions of humor. In J.H. Goldstein \& P.E. McGhee (Eds.), The psychology of humor (pp. 101-125). New York: Academic Press.

Olson, J.M, Maio, G.R., \& Hobden, K.L. (1999). The (null) effects of exposure to disparagement humor on stereotypes and attitudes. Humor: International Journal of Humor Research. 12, 195-219.

Greengross, G. \& Miller, G.F. (2008). Dissing oneself versus dissing rivals: Effects of status, personality, and sex on the short-term and long-term attractiveness of self-deprecating and other-deprecating humor. Evolutionary Psychology, 6, 393-408.

Ryan, K.M. \& Kanjorski, J. (1998). The enjoyment of sexist humor, rape attitudes, and relationship aggression in college students. Sex Roles, 38, 743-756.

Stocking, S.H. \& Zillmann, D. (1976). Effects of humorous disparagement of Self, friend, and enemy. Psychological Reports, 39, 455-461.

Stocking, S.H., Sopolsky, B.S., \& Zillmann, D. (1977). Sex discrimination in prime time humor. Journal of Broadcasting, 21, 447-457.

Tajfel, H. (1970). Experiments in intergroup discrimination. Scientific American, 223, 96-102.

Tajfel, H. (1978). The psychological structure of intergroup relations. In H. Tajfel (Ed.), Differentiation between social groups: Studies in the social psychology of intergroup relations. London: Academic Press.

Tajfel, H., \& Turner, J.C. (1986). The social identity theory of intergroup behavior. In Austin, William G., Stephen Worcheland (Eds.), Psychology of Intergroup Relations (pp. 7-24). Chicago: Nelson-Hall.

Thomas, C.A. \& Esses, V.M. (2004). Individual differences in reactions to sexist humor. Group Processes and Intergroup Relations, 7, 89-100.

Torrance, E.P. (1962). Guiding creative talent. Englewood Cliffs, NJ: Prentice-Hall. 
Torrance, E. P. (1966). The Torrance Tests of Creative Thinking-Norms-Technical Manual Research Edition-Verbal Tests, Forms A and B-Figural Tests, Forms A and B. Princeton NJ: Personnel Press.

Torrance, E. P. \& Presbury, J. (1984). The criteria of success used in 242 recent experimental studies of creativity. Creative Child \& Adult Quarterly, 9, 238-243.

Torrance, E. P. \& Safter, H. T. (1989). The long range predictive validity of the Just Suppose Test. Journal of Creative Behavior, 23, 219-223.

Twain, M. (1893). Pudd'nhead Wilson. Charles L. Webster \& Co.

Webster's New World Dictionary, 2002. John Wiley \& Sons.

Wicker, F.W., Baron, W.L. \& Willis, A.C. (1980). Disparagement humor: Dispositions and resolutions. Journal of Personality and Social Psychology, 39, 701-709.

Wilson, C.P. (1979). Jokes: Form, content, use, and function. New York: Academic Press.

Wolff, H. A., Smith, C. E. \& Murray, H. A. (1934). The psychology of humor: A study of responses to race-disparagement jokes. Journal of Abnormal and Social Psychology, 28, 341-365.

Zillmann, D. (1983). Disparagement humor. In P.E. McGhee \& J.H. Goldstein (Eds.), Handbook of humor research (pp. 85-108). NY: Springer-Verlag.

Zillmann, D. \& Bryant, J. (1980). Misattribution theory of tendentious humor. Journal of Experimental Social Psychology, 16, 146-160.

Zillmann, D. \& Cantor, J.R. (1996). A disposition theory of humor and mirth. In A.J. Chapman \& H.C. Foot (Eds.), Humor and laughter: Theory, research, and applications (pp. 93-116). NY: Wiley.

About the Authors:

Leslie M. Janes

Leslie M. Janes is an Associate Professor in the Psychology Department at Brescia University College in London, Canada. Her research interests include humor, motivation, and personality variables relating to resource allocation. 
Address correspondence to: Leslie Janes, Psychology Department, 1285 Western Road, London, Ontario, Canada, N6G 1H2

E-mail: ljanes@uwo.ca

James M. Olson

James M. Olson is a Professor in the Psychology Department at the University of Western Ontario, London, Canada, where he served as Chair of the department from 1998 to 2003. His research interests include humor, attitudes, and the social psychology of justice. He has published more than 100 articles and chapters and has edited 10 books. He is a co-organizer of the Ontario Symposium on Personality and Social Psychology. 